\title{
Architecture of a MicroRNA-controlled Gene Regulatory Network That Diversifies Neuronal Cell Fates
}

\author{
O. HOBERT \\ Howard Hughes Medical Institute, Department of Biochemistry and Molecular Biophysics, \\ Columbia University Medical Center, New York, New York 10032
}

\begin{abstract}
Individual cell types are defined by the expression of specific gene batteries. Regulatory networks that control cell-typespecific gene expression programs in the nervous system are only beginning to be understood. This paper summarizes a complex gene regulatory network, composed of several transcription factors and microRNAs (miRNAs), that controls neuronal subclass specification in the nervous system of the nematode Caenorhabditis elegans.
\end{abstract}

One of the key problems in developmental biology is to understand how cells within individual tissue types diversify their terminal differentiation programs. This is particularly evident in the nervous systems, where an impressive number of cells diversify from a neuronal ground state. This ground state is characterized by the expression of a generic set of neuronal function genes, such as components of the synaptic vesicle machinery, whereas neuron-specific states are characterized by a unique combinatorial expression profile of factors that define individual properties of each neuron, such as its specific morphological features or electrical properties. The human nervous system is estimated to contain $10^{11}$ neurons that generate $10^{14}$ connections, thereby illustrating the daunting nature of the task of understanding how such complex systems develop.

The diversification of individual cell types in the nervous system can be well studied in much simpler model organisms, such as the nematode $C$. elegans, which contains a nervous system of 302 cells (for a more detailed discussion, see Hobert 2006). These 302 cells fall into more than 100 different classes that can be distinguished by defined anatomical criteria (White et al. 1986). Most neuron classes can be further subdivided into subclasses (Hobert 2006). Members of a neuronal subclass are similar with regard to many properties, such as anatomical features and/or shared gene expression programs, but they can differ in very specific functional or morphological features. Examples include midline motor neuron classes, each of which is composed of individual subclasses that can only be distinguished by their specific axonal projection patterns (White et al. 1986). Other examples include bilaterally symmetric pairs of sensory neurons that have functionally diversified to express distinct classes of chemosensory receptors on the left and right side of the animal, as further discussed in this paper.

\section{THE ASE GUSTATORY NEURONS}

The ASE gustatory neuron class is one of several chemosensory neuron classes in the main head ganglia of the worm (Fig.1a) (Bargmann and Horvitz 1991). Each of these chemosensory neuron classes is composed of two bilaterally symmetric neurons that are indistinguishable by morphological criteria and in most cases examined also display the same functional properties (White et al. 1986; Hobert et al. 2002; Bergamasco and Bazzicalupo 2006). The ASE neuron class, however, is functionally lateralized in that it expresses distinct chemosensory properties on the left and right side of the animal. The ASEL (left) neuron primarily senses sodium, whereas the ASER (right) neuron primarily senses chloride and potassium (Fig.1b) (Pierce-Shimomura et al. 2001). The left/right asymmetric distribution of these chemosensory capacities correlates with the left/right asymmetric expression of a family of putative chemoreceptor genes (Fig.1b) (Yu et al. 1997; Ortiz et al. 2006).

The diversification of the anatomically symmetric ASE neurons into two functionally distinct neurons bears conceptual similarity to a poorly understood but fundamental property of most nervous systems. By anatomical and molecular criteria, most nervous systems display striking patterns of overall bilateral symmetry, yet as best exemplified in the anatomically bilaterally symmetric human brain, nervous systems display striking degrees of functional laterality (Davidson and Hugdahl 1994); that is, the left side of the brain performs tasks different from those of the right side of the brain and vice versa. How functional laterality is superimposed on a presumed bilaterally symmetric ground state is poorly understood. The ASE neuron class promises to yield insights into how the nematode C. elegans has solved this problem.

\section{A GENETIC ANALYSIS OF ASE CELL FATE SPECIFICATION REVEALS A BISTABLE REGULATORY SYSTEM}

Like nervous system laterality in general, ASE laterality appears to develop from a bilaterally symmetric ground state, characterized by the initially symmetric expression of genes that become restricted to either the ASEL or ASER neuron after hatching of the animal (Fig.1c) (Johnston et al. 2005). How is this switch from symmetry to asymmetry genetically programmed? The genetic amenability of $C$. elegans has enabled us to con- 
a

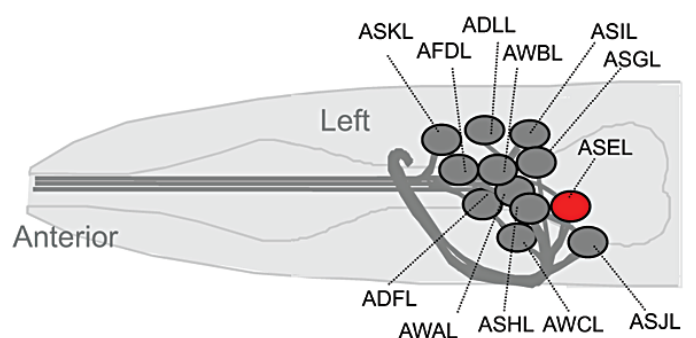

b

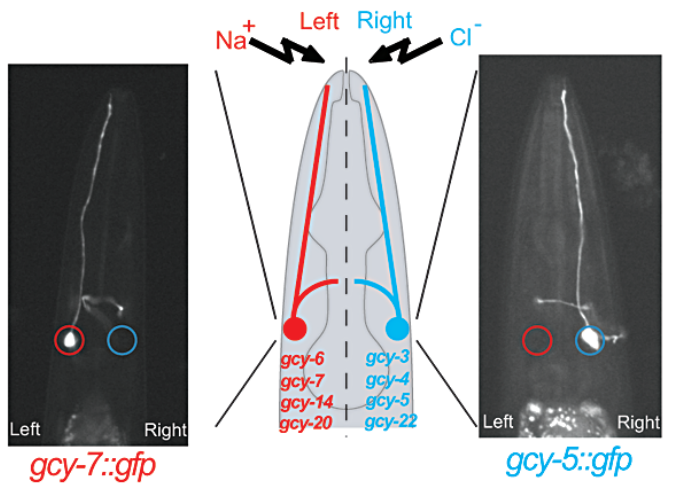

C

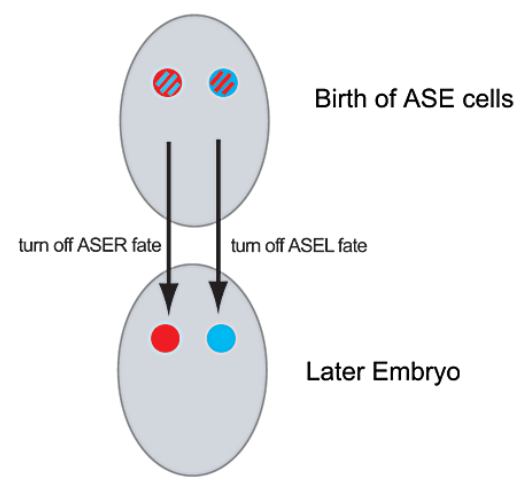

Figure 1. Left/right asymmetry in the ASE gustatory neurons. (a) Chemosensory system of C. elegans. Lateral view. Only amphid-type chemosensory neurons are shown. (b) The ASE neurons. ASEL and ASER sense different ions and express distinct putative chemoreceptors of the gcy gene family (Yu et al. 1997; Pierce-Shimomura et al. 2001; Ortiz et al. 2006). (c) ASE asymmetry develops from a hybrid precursor state, characterized by the initial coexpression of lateral markers (Johnston et al. 2005).

duct large-scale genetic screens for mutants in which the left/right asymmetric expression of green fluorescent protein (GFP)-tagged terminal cell fate markers are affected ("lsy" phenotype for "lateral symmetry-defective"). So far, we have screened through more than 100,000 haploid genomes, which according to the estimated average mutation frequency, represents an $\sim 50 \mathrm{x}$ coverage of the whole genome (Chang et al. 2003, 2004; Johnston and Hobert 2003, 2005; Johnston et al. 2006; O. Hobert et al., unpubl.). We have retrieved almost 200 mutant alleles in which distinct aspects of expression of laterally expressed $g f p$ markers are affected (O. Hobert et al., unpubl.). The mutant alleles define at least 20 complementation groups. Most mutants can be classified into at least four distinct a

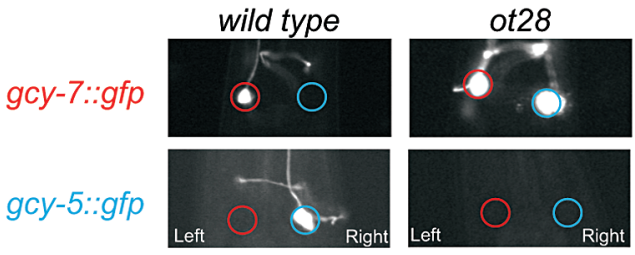

b

\section{Class II mutant}

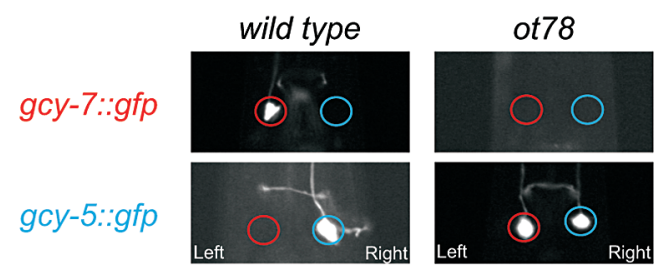

C
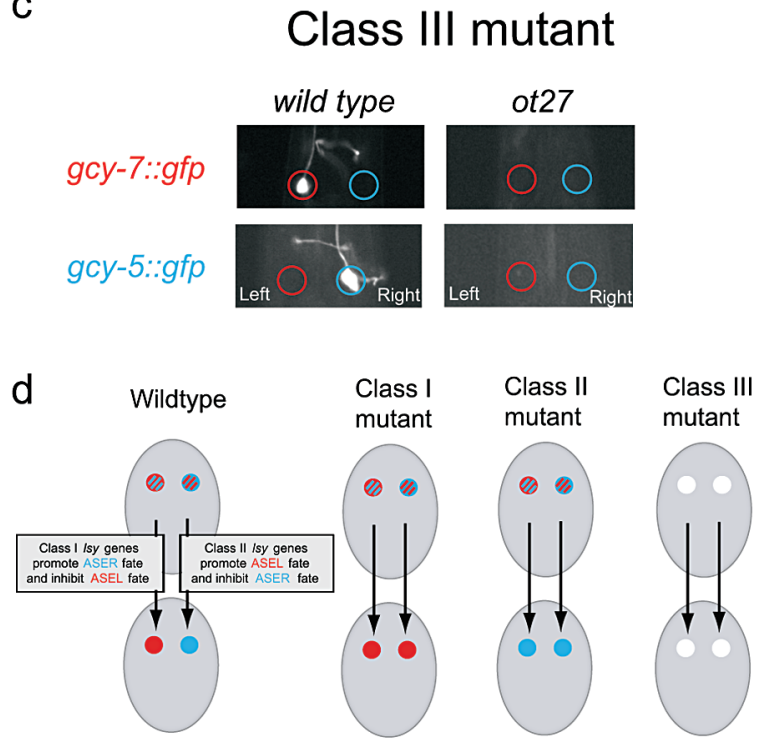

e

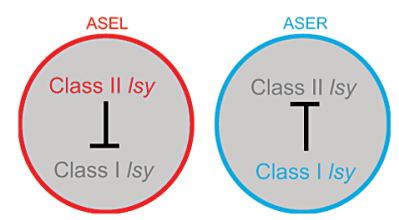

Figure 2. Mutant screen reveals several classes of ASE mutants. (a) Class I mutants display a "2 ASEL" phenotype. The cog-1(ot28) allele is shown as a representative example (Chang et al. 2003). (Red circles) ASEL cell position; (blue circles) ASER position. (b) Class II mutants display a "2 ASER" phenotype. The lin-49(ot78) allele is shown as a representative example (Chang et al. 2003). (c) Class III mutants display a "no ASE" phenotype. The che-1(ot27) allele is shown as a representative example (Chang et al. 2003). (d) Schematic representation of ASE fate specification from a "hybrid precursor state" (Johnston et al. 2005) to a mature L/R asymmetric state and mutant phenotypes. The progression from hybrid to asymmetric occurs in the embryo. (e) Class I and class II genes define a bistable system that depends on mutual inhibition. 
Table 1. Identity of Genes That Affect ASE Differentiation

\begin{tabular}{|c|c|c|c|c|c|}
\hline Gene & $\begin{array}{l}\text { Mutant } \\
\text { class }\end{array}$ & Molecular features & Expression & $\begin{array}{l}\text { Instructive vs. } \\
\text { permissive }^{\mathrm{a}}\end{array}$ & References \\
\hline$\overline{\operatorname{cog}-1}$ & Class I & Nk-type homeobox & ASER & $\mathrm{I}$ & Chang et al. (2003) \\
\hline unc-37 & Class I & $\begin{array}{l}\text { WD40 domain } \\
\text { (Groucho ortholog) }\end{array}$ & ASEL + ASER & $P$ & Chang et al. (2003) \\
\hline $\begin{array}{l}\text { mir-273 } \\
\quad \text { family members }\end{array}$ & Class I ${ }^{\mathrm{b}}$ & miRNA & ASEL $<$ ASER & I & $\begin{array}{l}\text { Chang et al. (2004); O. } \\
\text { Hobert et al. (unpubl.) }\end{array}$ \\
\hline ceh-36 & Class II & Otx-type homeobox & ASEL + ASER & $\mathrm{P}$ & Chang et al. (2003) \\
\hline die-1 & Class II & zinc fingers & ASEL & I & Chang et al. (2004) \\
\hline$l s y-2$ & Class II & zinc fingers & ASEL + ASER & $\mathrm{P}$ & Johnston and Hobert (2005) \\
\hline $\operatorname{lin}-49$ & Class II & $\begin{array}{l}\text { PHD finger, } \\
\text { bromodomain }\end{array}$ & ASEL + ASER & $\mathrm{P}$ & Chang et al. (2003) \\
\hline$l s y-6$ & Class II & miRNA & ASEL & I & Johnston and Hobert (2003) \\
\hline $\begin{array}{l}\text { che-1 } \\
\text { lim- } 6\end{array}$ & $\begin{array}{l}\text { Class III } \\
\text { Class IV }\end{array}$ & $\begin{array}{l}\text { zinc fingers } \\
\text { LIM homeobox }\end{array}$ & $\begin{array}{l}\text { ASEL + ASER } \\
\text { ASEL }\end{array}$ & $\begin{array}{l}\mathrm{P} \\
\mathrm{I}\end{array}$ & $\begin{array}{l}\text { Chang et al. (2003) } \\
\text { Hobert et al. (1999) }\end{array}$ \\
\hline fozi-1 & Class IV & zinc fingers & ASER & I & Johnston et al. (2006) \\
\hline
\end{tabular}

aA factor is termed "instructive" if it is not only required for the execution of a specific fate, but also sufficient, if misexpressed. In contrast, "permissive" factors are only required but not sufficient for the execution of a specific fate.

${ }^{\mathrm{b}}$ This phenotype is inferred from ectopic expression analysis, not from mutant analysis.

classes (Fig. $2 \mathrm{a}-\mathrm{d}$ ). In class I $l$ sy mutants, both ASEL and ASER express the ASEL expression profile and the ASER expression profile is lost (Fig. 2a); in class II $l s y$ mutants, both ASEL and ASER express the ASER expression profile, and the ASEL expression profile is lost (Fig. 2b); in class III $l s y$ mutants, all ASE-specific genes fail to be expressed (Fig. 2c); and in class IV lsy mutants, either the ASEL or the ASER cell expresses mixed ASEL/ASER fate characteristics. We have determined the molecular identity of some genes from each of these categories and found that they all encode gene regulatory factors, including sequence-specific DNA-binding transcription factors, general transcriptional cofactors, and miRNAs (Table 1).

The mutant phenotypes, expression pattern, and epistatic relationship of the uncovered gene regulatory factors revealed an important feature of the regulatory architecture of ASEL/R fate specification. The system classifies as a bistable system that, depending on the activity of specific regulatory factors, can exist in one of two stable states: the ASEL state or the ASER state (Johnston et al. 2005). Class I $l s y$ genes control the ASER state through repression of class II $l s y$ genes, which control the ASEL state through repression of class I $l s y$ genes (Fig. 2e). Loss of class I $l s y$ genes therefore leads to ectopic expression of class II $l s y$ genes and execution of the ASEL fate in both cells, and vice versa.

\section{THE BISTABLE SYSTEM IS CONTROLLED BY MIRNAS}

The class II gene $l s y-6$ and the class I gene $\operatorname{cog}-1$ are two representative class I and class II genes that regulate each other's expression (Fig. 3a). We first discuss the regulation of $\operatorname{cog}-1$ by $l s y-6$, which represents a prime paradigm for one of the very few biologically validated animal miRNA/target interactions (Johnston and Hobert 2003; Ambros 2004; Carthew 2006). Mapping of the $l s y$ 6 locus, of which we retrieved at least four mutant alle- les, revealed that $l s y-6$ codes for a 21 -nucleotide-long miRNA that binds to a single complementary site in the 3 'UTR (untranslated region) of the $\operatorname{cog}-1$ homeobox gene (Fig. 3b). This interaction apparently only occurs in a single cell type, ASEL, since $\operatorname{cog}-1$ and $l s y-6$ are expressed in an otherwise nonoverlapping set of neuronal and nonneuronal cells (Fig. 3c). The cell-type specificity in the overlap of a regulatory gene and its target gene is also a common theme in transcriptional regulation (see, e.g., Altun-Gultekin et al. 2001; Tsalik and Hobert 2003). The functional interaction of $l s y-6$ with $\operatorname{cog}-1$ was validated using a sensor gene strategy in which the promoter of the ceh-36 gene drives $g f p$ expression in ASEL and ASER; substituting a nonregulated 3'UTR with the 3'UTR of the cog-1 gene causes downregulation of this sensor in ASEL but not in ASER (Fig. $3 d)$. This down-regulation depends on the presence of the $l s y-6$ miRNA and the $l s y-6$ complementary site in the cog-1 3'UTR (Fig. 3d).

Notably, at first appearance, $l s y-6$ affects $\operatorname{cog}-1$ transcription, that is, the ASEL neuron, which expresses $l s y$ 6 , does not transcribe $\operatorname{cog}-1$ (a surprising notion since it would suggest that $l s y-6$ and $\operatorname{cog}-1$ mRNA will not encounter each other); yet, removal of $l s y-6$ leads to aberrant transcription of $\operatorname{cog}-1$ in ASEL (Johnston et al. 2005). We have shown that this phenomenon is explained through positive transcriptional autoregulation of $\operatorname{cog}-1$ (Johnston et al. 2005). In the presence of $l s y-6$, COG-1 protein is not produced, and since COG-1 protein autoregulates its own transcription, the $\operatorname{cog}-1$ mRNA will also disappear. Thus, a lack of overlap in the expression of miRNAs and predicted target genes, which is observed frequently (Stark et al. 2005), may therefore, at least in some cases, be a consequence of miRNA-target interaction, rather than a reflection of evolutionary divergence in transcriptional control of miRNAs and their target genes.

Contrasting proposed models that posit a prevailing theme of miRNAs as fine-tuners of gene expression or 
a

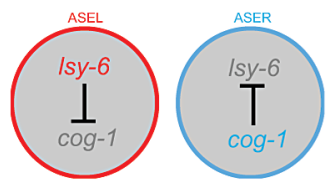

b

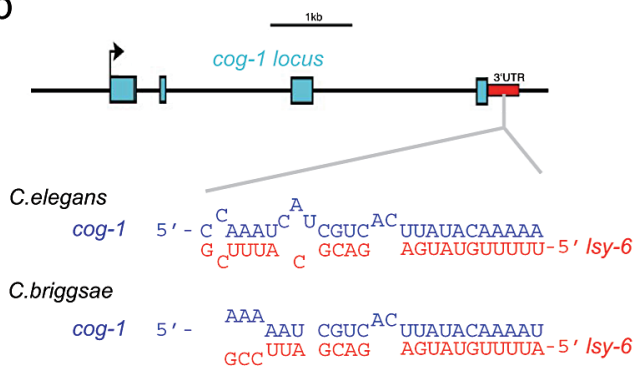

C

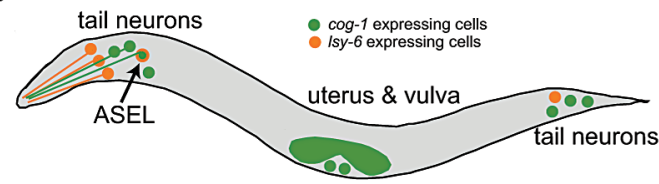

d
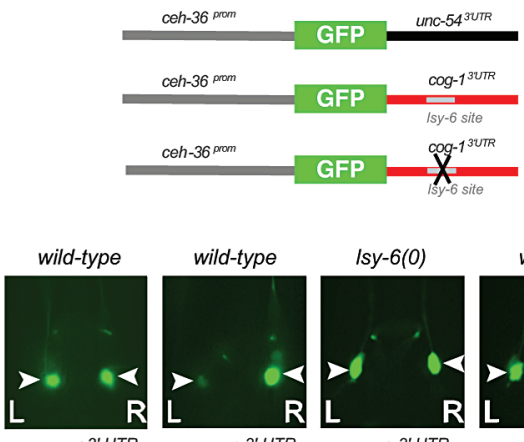

wild-type
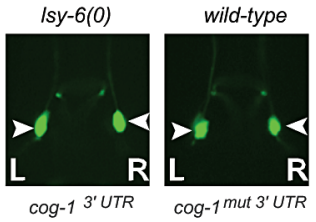

e

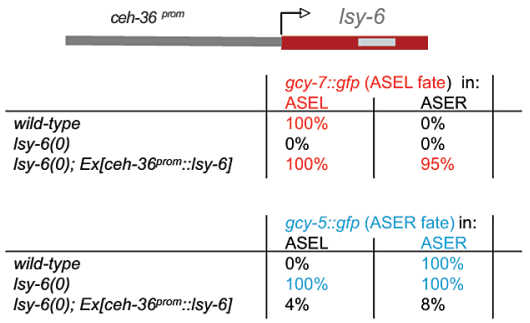

Figure 3. The $l s y-6 / \operatorname{cog}-1$ interaction. (a) $l s y-6$ and $\operatorname{cog}-1$ define two mutual inhibitory class I and class II genes. (b) The $\operatorname{cog}$ - $13^{\prime} \mathrm{UTR}$ contains a $l s y-6$ complementary site, which is phylogenetically conserved (Johnston and Hobert 2003). The seed region within the $\operatorname{cog}-1 / l s y-6$ is required but not sufficient to confer $\operatorname{cog}-1$ down-regulation by $l s y-6$ (Didiano and Hobert 2006). (c) $l s y-6$ and $\operatorname{cog}-1$ expression only overlaps in ASEL. The $g f p$-tagged $\operatorname{cog}-1$ locus is expressed in the ADL, ASE, ASJ, AIA (or SMBD, SIAD, or SIAV), and PHB neuron classes, in unidentified preanal ganglion neurons, sphincter muscle, phasmid sheath cells, uterus, and the developing vulva (Palmer et al. 2002). The $g f p$-tagged $l s y$ - 6 locus is expressed in six labial sensory neurons, ASEL and the PVQ neuron class in the tail (Johnston and Hobert 2003). (d) Down-regulation of the cog-1 3'UTR by lsy-6 can be monitored using a sensor gene strategy (Johnston and Hobert 2003; Didiano and Hobert 2006). (e) $l s y$-6 works as a switch. $l s y-6$ is both necessary and sufficient to induce the ASEL fate (Johnston and Hobert 2003).

buffers of "genetic noise" (Bartel and Chen 2004; Stark et al. 2005; Hornstein and Shomron 2006), $l s y-6$ acts as a switch in the ASE fate decision. Loss of $l s y-6$ causes the ASEL neuron to switch to the execution of ASER fate, and ectopic expression of $l s y-6$ in the ASER neuron switches on ASEL fate in ASER (Fig. 3e) (Johnston and Hobert 2003).

$\operatorname{cog}-1$ is not only directly regulated by $l s y-6$, but is also itself required for regulation of $l s y-6$ expression. This feedback mechanism is complex and involves a series of additional factors. $l s y-6$ expression in ASEL is controlled by the ASEL-specific zinc finger transcription factor die-1, a class II $l s y$ gene, retrieved from our mutant screen (Fig. 4) (Chang et al. 2004). The L/R asymmetric expression of die-1 is controlled via the $3^{\prime}$ UTR of die-1, as revealed by a sensor gene approach similar to that used for $\operatorname{cog}-1$. The ASER-specific down-regulation of the $3^{\prime}$ UTR of die- 1 genetically depends on $\operatorname{cog}-1$, indicating that $\operatorname{cog}$ 1 genetically activates posttranscriptional factors that negatively regulate die-1 (Johnston et al. 2005). The mir-273 family of miRNAs, composed of at least seven members (mir-273, mir-51 through mir-56) are excellent candidates to be involved in this process. First, the die-1 3'UTR contains two phylogenetically conserved complementary sites to mir-273 family members; second, some members of the family are predominantly expressed in ASER, where the die-1 3'UTR is down-regulated (Chang et al. 2004; O. Hobert et al., unpubl.); third, the ASER-biased expression of mir-273, and likely other family members as well, is lost in cog-1 mutants (Johnston et al. 2005); and fourth, forced expression of mir-273 or other members of the family in ASEL induces ASER fate in ASEL (Chang et al. 2004; O. Hobert et al., unpubl.), as would be expected from a down-regulation of die-1 expression.

lsy-6, cog-1, die-1, and mir-273 family members therefore define a double-negative feedback loop (Fig. 5a) that provides the underlying molecular basis for the bistability of the system. A number of prominent and well-studied cell fate decisions utilize bistable feedback systems to control specific cell fate decisions. Examples include the bacteriophage $\lambda$ system, which relies on mutual cross-inhibition of two repressor proteins, $\mathrm{Cl}$ and $\mathrm{Cro}$ (Fig. $5 \mathrm{c}$ ). In a more complex example, a specific cell fate decision in the worm's developing vulva is controlled by a Notch/lin-12-mediated negative feedback loop between two distinct cells (Fig. 5d).

Feedback loops require the existence of specific inputs into the loop and outputs from the loop (Fig. 5e). Through genetic epistasis analysis, we determined the input and output of the ASEL/R-controlling bistable feedback loop (Johnston et al. 2005). One representative example of this type of analysis is shown in Figure 4. The key points of the epistasis analysis are that $l s y-6$ requires all loop components to affect terminal differentiation markers (such as the $g c y$ genes or lim-6), whereas, in contrast, die-1 can exert its effect on terminal differentiation markers independently of the loop components (Fig. 4). $l s y$-6 therefore provides the input into the loop, and die-1 is the output regulator (Fig. 5a). 
a

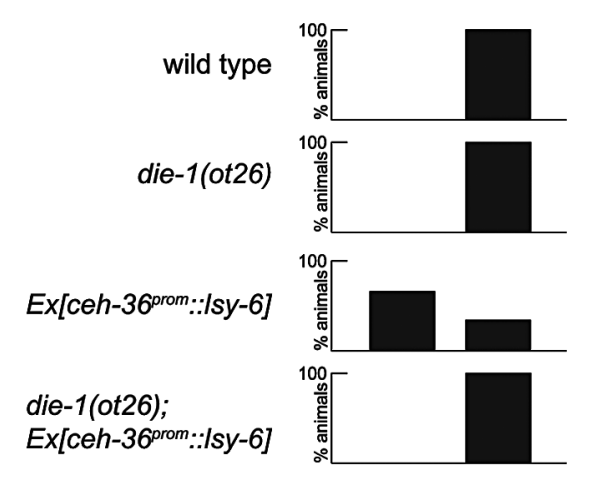

b

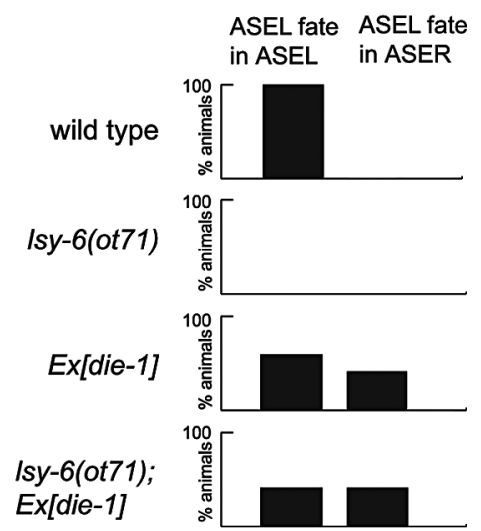

Figure 4. Determining regulatory architecture through epistasis analysis. Two examples of the genetic epistasis analysis. ASEL

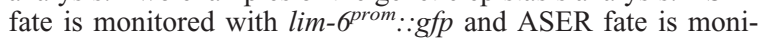
tored with $g c y-5^{\text {prom }}: \because g f p$. "Ex" indicates the forced, bilateral expression of regulatory factors from extrachromosomal arrays. (a) Ectopic $l s y$ - 6 requires die- 1 to induce ASEL fate. (b) Ectopic die- 1 does not require $l s y-6$ to induce ASEL fate. (Modified, with permission, from Johnston et al. 2005 [C National Academy of Sciences].)

The regulatory architecture downstream from die- 1 is complex. The precise quantification of mutant phenotypes as well as epistasis analysis indicates that die- 1 acts in the context of several feedforward loop motifs to affect terminal differentiation markers, such as the chemoreceptors of the $g c y$ family or neuropeptides of the flp family (Fig. 5b). To be expressed, several of these terminal differentiation markers usually require two conditions: the presence of die- 1 and the absence of a die-1-repressed zinc finger transcription factor, fozi-1, a class IV mutant retrieved from our screen (Fig. 2d) (Johnston et al. 2006). The absence of die1 in ASER allows expression of this zinc finger transcription factor, thereby repressing the expression of a repressor of the ASER fate, the lim-6 LIM homeobox gene. The sequential repression cascade that abounds in the ASEL/R regulatory architecture falls well in line with observations in the vertebrate nervous system, where the sequential repression of transcriptional repressor proteins diversifies neuronal cell fate in the spinal cord (Muhr et al. 2001).

A central feature of these sequential repression schemes is a permissive activation mechanism. This can be illustrated in the case of the ASER-specific gcy genes. As shown in Figure 5a, their expression is regulated by the repression of repressor proteins, but eventually factors must exist to turn on the expression of the ASER-specific gcy genes. Our large-scale mutant analysis, in combination with the molecular dissection of the cis-regulatory architecture of ASE-expressed genes, revealed a factor that is an excellent candidate to provide such permissive activation function. In class III mutants, all ASE-expressed genes fail to be activated; all class III mutant alleles that we retrieved from our genetic screens ( $>20$ alleles) define a single locus, che-1. che-1 encodes a zinc finger transcription factor expressed in both ASEL and ASER (Chang et al. 2003; Uchida et al. 2003), which we found to bind to an experimentally determined binding site, termed the "ASE motif" that is present in all ASE-expressed genes (J. Etchberger and O. Hobert et al., unpubl.). The CHE-1 protein therefore defines a "ground state" of activation, which is modified through the sequential activity of repressors. This model also provides a mechanistic basis for the observation that directly after their birth, both the ASEL and ASER neurons coexpress genes that later become restricted to either ASEL or ASER (e.g., both $l s y-6$ and $\operatorname{cog}-1$ are initially coexpressed) (Johnston et al. 2005). Presumably, these genes are first all activated by CHE-1 and then become sequentially repressed in either ASEL or ASER.

\section{INTRODUCING THE LEFT/RIGHT BIAS}

A central question that is left unanswered so far is what determines the left/right differential activity of the bistable feedback loop. Why do $l s y-6$ and die-1 "win" in ASEL, and $\operatorname{cog}-1$ and the mir-273 family "win" in ASER? At first sight, an attractive underlying mechanism could have been some form of lateral inhibition, best studied in the case of the AC/VU cell fate decision (Fig. 5d). An apparently stochastic small difference in the level of Notch/lin12 activity is amplified by a feedback mechanism, so that the presumptive AC cell ultimately expresses only the lin12 ligand lag-2, whereas the presumptive VU cell expresses only lin-12 (Greenwald 1998). Such a mechanism is, however, unlikely to exist in the ASE fate decision. First, in contrast to the AC/VU decision and other lateral inhibition phenomena, the process is not stochastic; i.e., the right cell always adopts the ASER fate and the left cell always adopts the ASEL fate. Second, laser ablation studies reveal that ASEL is not required for the adoption of the ASER fate, and ASER is not required for the adoption of the ASEL fate (Poole and Hobert 2006).

The progression of the system from a hybrid precursor state to an asymmetric state some time in late embryogenesis, after the cells are born, could, in theory, be explained by the existence of a nonautonomous signal that instructs either ASEL or ASER to become different from one another. For example, both cells could contain an intrinsic bias to one loop configuration, e.g., the ASER-promoting configuration, and a signal to ASEL could reverse the loop (e.g., by boosting $l s y-6$ expression) to the opposite configuration. In this simple form, this model is also unlikely to be correct. Genetic and surgical manipulation in the early embryo rather suggest that the difference between ASEL and ASER is already predeter- 
a

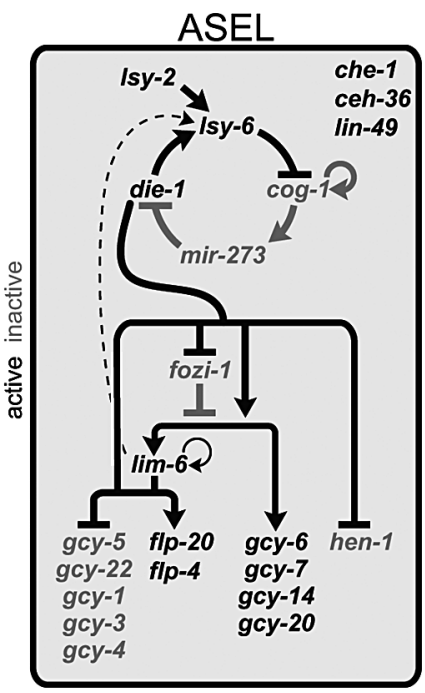

ASER

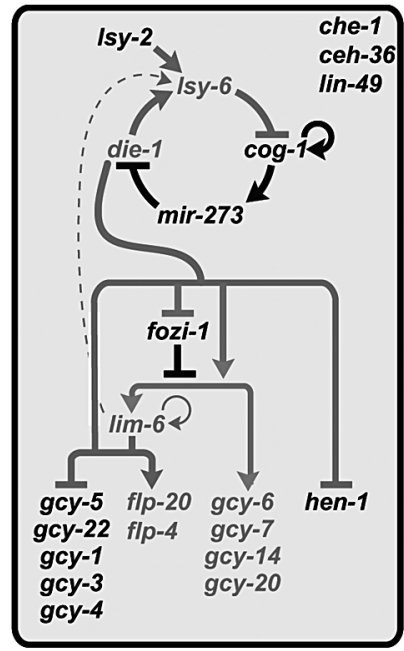

b

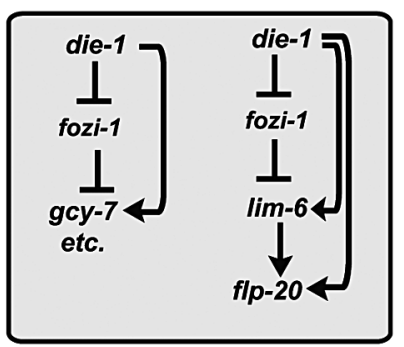

C

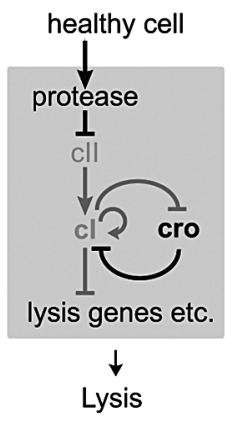

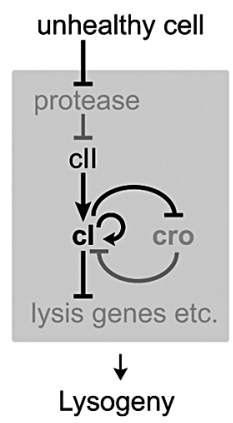

d

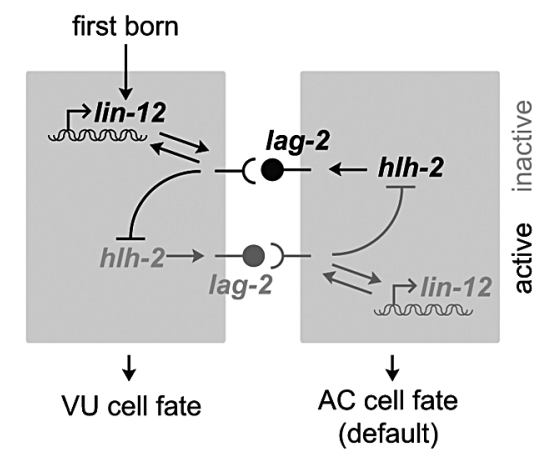

e

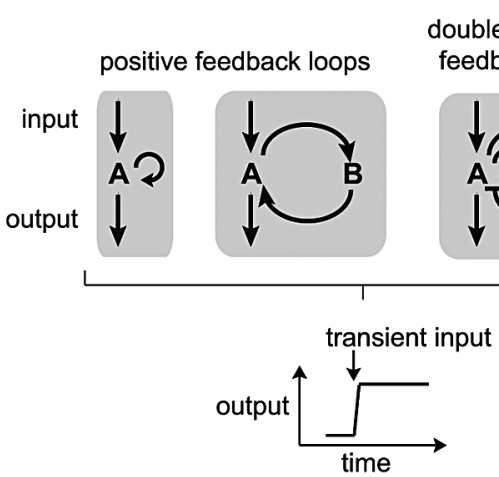

double-negative feedback loop

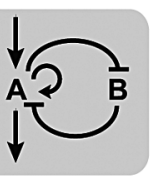

(
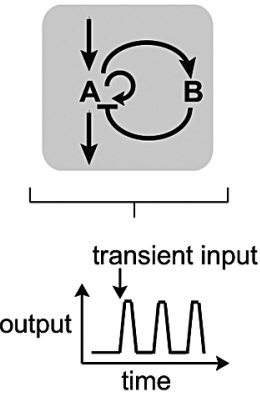

f

single-negative
feedback loop

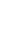

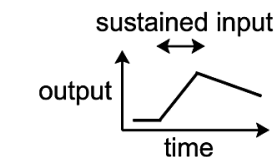

Figure 5. Regulatory architecture of cell fate specification events. (a) Regulatory architecture of ASEL/R fate specification. At present, it is not known where the permissively acting (i.e., ASEL/ASER-expressed) transcription factors ceh-36 and lin-49 fit into the gene regulatory network. The zinc finger transcription factor encoded by the che-1 gene appears to be required for the activation of each ASEL or ASER expressed gene. (b) Deconvoluted network motifs extracted from panel $a$ (Poole and Hobert 2006). (c,d) Bistable, negative feedback loops control fate decisions in other systems. Examples are the bacteriophage $\lambda$ (panel $c$ ) (Ptashne 1992) and the AC/VU decision in C. elegans (panel $d$ ) (Greenwald 1998). $(e, f)$ Network motifs and their properties. (c,d,e, Reprinted, with permission, from Johnston et al. 2005 [ National Academy of Sciences].)

mined at the level of very early blastomere identity, long before the ASE cells are born (Poole and Hobert 2006). One attractive possibility is that this early determination event is memorized through embryonic development until after the ASE cells are born by a chromatin-related mechanism that may bias the expression of loop components in the left cell versus the right cell. We anticipate that our ongoing genetic and molecular analyses of the many more mutants that affect ASEL/R fate specification will eventually resolve this question. 


\section{NETWORK MOTIFS}

Work in simple unicellular organisms during the past few years revealed that networks of regulatory factors contain recurring wiring patterns termed "network motifs" (Lee et al. 2002; Milo et al. 2002; Shen-Orr et al. 2002). ASEL/R specification also involves several of these network motifs, namely, feedback and feedforward loops (Fig. 5) (Johnston et al. 2005, 2006). These network motifs have defined properties that may be useful to understand ASEL/R fate determination. Feedback loops have the feature of being able to amplify a transient and weak input into a robust output (Fig. 5e). Feedforward loops (Fig. 5f) are persistence detectors that measure the sustained presence of a factor A. Only if A is present long enough to activate factor $\mathrm{B}$ can it activate, together with factor B, the target gene T (Fig. 5f).

A working hypothesis for the ASEL/R fate determination process is therefore that an initial slight difference between ASEL and ASER, possibly determined by a signal into lineage precursors of ASEL/R, is amplified after the birth of the ASE neurons. The amplification of this input may be measured on the level of die- 1 and the feedforward motifs that emanate from die-1. Only if die-1 levels have reached a certain level for a long enough time ("persistence detection") will downstream target genes be activated. Further genetic analysis will reveal additional gene regulatory factors in this network and will lead to a deeper understanding of the intricate interplay between these regulatory factors.

\section{OPEN QUESTIONS}

Our analysis has only begun to reveal the regulatory logic of ASE neuron specification. The many open questions that remain include (1) What is the molecular nature of the input into the bistable feedback loop, that is, what biases the loop into one configuration in ASEL and into the other configuration in ASER? (2) What other regulatory factors are embedded within the bistable feedback loop and within the feedforward loops that control the terminal differentiation markers, or, in other words, which of the interactions shown in Figure 5a are direct, which are indirect? (3) How is the activity of permissively acting factors, such as ceh-36, lsy-2, and lin-49, which are expressed in both ASEL and ASER (Table 1), restricted to either ASEL or ASER? We anticipate that the cloning of mutants from our large mutant collection and biochemical approaches aimed at looking at protein/nucleic acid interactions directly in the ASE neurons may answer these and other remaining questions.

\section{CONCLUSIONS}

Gene regulatory networks that control terminal cell fates can be surprisingly complex. With its attempt to provide a saturation analysis of a depth similar to the genetic analysis of early fly embryo patterning (Nüsslein-Volhard and Wieschaus 1980), it is perhaps not surprising that our large-scale genetic analysis has uncovered an intricate network of gene regulatory factors. Other cell fate decisions may be similarly controlled by complex networks, to be revealed by, for example, saturation mutant analysis. But it is also conceivable that some cell fate decisions involve more complex regulatory networks than others. This could be envisioned to be the case if one deals with diversifying the fate of cells that are largely similar to one another. Generating a group of cells with similar fates may impose regulatory constraints that may require complex changes in the regulatory wiring to further diversify individual cells within this group. The diversification of the cellular fate of ASEL and ASER is indeed a relatively recent evolutionary phenomenon since the expression of the gcy chemoreceptors is differently controlled in two related nematode species (Ortiz et al. 2006).

Given the youth of the miRNA field and the resulting paucity of experimental data on miRNA function, our studies have revealed and corroborated previous insights into miRNA function (for general reviews on miRNA function in vivo, see Ambros 2004; Carthew 2006). One theme that deserves emphasis is that gene regulation mediated by miRNAs shares many conceptual similarities with gene regulatory events mediated by transcription factors (Hobert 2004). Like transcription factors, miRNAs bind to specific cis-regulatory elements in their nucleic acid target sequences (DNA for transcription factors, RNA for miRNAs). Like cis-regulatory elements hardwired into DNA, miRNA-responsive cis-regulatory elements in mRNAs are (1) occupied in a cell-type-specific manner by trans-acting factors, i.e., cell-type-specifically expressed miRNAs and (2) they are functional only in a highly context-dependent manner (Didiano and Hobert 2006). Like transcription factors, miRNAs appear to be integrated into gene regulatory networks. They are activated by RNA polymerase-II-dependent transcription factors and control the expression of transcription factors. Like ASEexpressed transcription factors, miRNAs acting in ASE cell fate specification work as clear switches and are necessary and sufficient to induce specific cellular fates.

The so far exclusive role of miRNAs in repression of target gene expression also fits with recent themes that propose that transcription factors which determine cellular fate often act as repressors; that is, to induce a specific cell fate, one does not necessarily require a specific gene activation event, but the specific modulation of a repressed state (Muhr et al. 2001).

Since we are still in the early days of studying miRNA function, it appears premature to propose overarching, global themes of miRNA function. As the decades of work on transcription factors have taught us, large families of gene regulatory factors may easily escape an easy overall classification theme. A careful experimental analysis of miRNAs in diverse cellular contexts will ultimately reveal the full functional spectrum of this exciting class of RNA-based gene regulatory factors.

\section{ACKNOWLEDGMENTS}

The experiments presented here were conducted by a series of past and present students and postdocs. Sarah Chang and Bob Johnston identified, mapped, and cloned the genes presented here, and Bob Johnston determined the regulatory architecture of the genetic interactions. 
More recent screens on ASE cell fate determination were done by Celia Antonio, Eileen Flowers, Maggie O'Meara, and Sumeet Sarin. Work on the interactions of $l s y-6$ and cog-1 was done by Dominic Didiano, studies on che-1 were done by John Etchberger, and the early embryo work was done by Richard Poole and Bob Johnston. Thanks to members of the Hobert lab for commenting on the manuscript. This work was funded by the National Institutes of Health (2R01NS039996-05, 5R01NS050266-02) and by the Howard Hughes Medical Institute.

\section{REFERENCES}

Altun-Gultekin Z., Andachi Y., Tsalik E.L., Pilgrim D., Kohara Y., and Hobert O. 2001. A regulatory cascade of three homeobox genes, ceh-10, ttx-3 and ceh-23, controls cell fate specification of a defined interneuron class in $C$. elegans. Development 128: 1951.

Ambros V. 2004. The functions of animal microRNAs. Nature 431: 350 .

Bargmann C.I. and Horvitz H.R. 1991. Chemosensory neurons with overlapping functions direct chemotaxis to multiple chemicals in C. elegans. Neuron 7: 729.

Bartel D.P. and Chen C.Z. 2004. Micromanagers of gene expression: The potentially widespread influence of metazoan microRNAs. Nat. Rev. Genet. 5: 396.

Bergamasco C. and Bazzicalupo P. 2006. Chemical sensitivity in Caenorhabditis elegans. Cell. Mol. Life Sci. 63: 1510.

Carthew R.W. 2006. Gene regulation by microRNAs. Curr. Opin. Genet. Dev. 16: 203.

Chang S., Johnston R.J., Jr., and Hobert O. 2003. A transcriptional regulatory cascade that controls left/right asymmetry in chemosensory neurons of C. elegans. Genes Dev. 17: 2123.

Chang S., Johnston R.J., Frøkjaer-Jensen C., Lockery S., and Hobert O. 2004. MicroRNAs act sequentially and asymmetrically to control chemosensory laterality in the nematode. Nature 430: 785 .

Davidson R.J. and Hugdahl K., eds. 1994. Brain asymmetry. MIT Press, Cambridge, Massachusetts.

Didiano D. and Hobert O. 2006. Perfect seed pairing is not a generally reliable predictor for miRNA-target interactions. Nature Struct. Mol. Biol. 13: 849.

Greenwald I. 1998. LIN-12/Notch signaling: Lessons from worms and flies. Genes Dev. 12: 1751.

Hobert O. 2004. Common logic of transcription factor and microRNA action. Trends Biochem. Sci. 29: 462.

- 2006. Specification of the nervous system. In WormBook: The online review of $\mathrm{C}$. elegans biology. The C. elegans Research Community, eds. (www.wormbook.org).

Hobert O., Johnston R.J., Jr., and Chang S. 2002. Left-right asymmetry in the nervous system: The Caenorhabditis elegans model. Nat. Rev. Neurosci. 3: 629.

Hobert O., Tessmar K., and Ruvkun G. 1999. The Caenorhabditis elegans lim-6 LIM homeobox gene regulates neurite outgrowth and function of particular GABAergic neurons. Development 126: 1547.

Hornstein E. and Shomron N. 2006. Canalization of development by microRNAs. Nat. Genet. (suppl. 1) 38: S20.

Johnston R.J. and Hobert O. 2003. A microRNA controlling left/right neuronal asymmetry in Caenorhabditis elegans. Nature 426: 845. - 2005. A novel C. elegans zinc finger transcription fac- tor, 1sy-2, required for the cell type-specific expression of the 1sy-6 microRNA. Development 132: 5451.

Johnston R.J., Jr., Chang S., Etchberger J.F., Ortiz C.O., and Hobert O. 2005. MicroRNAs acting in a double-negative feedback loop to control a neuronal cell fate decision. Proc. Natl. Acad. Sci. 102: 12449.

Johnston R.J., Copeland J.W., Fasnacht M., Etchberger J.F., Liu J., Honig B., and Hobert O. 2006. An unusual $\mathrm{Zn}$ finger/FH2 domain protein controls a left/right asymmetric neuronal fate decision in C. elegans. Development 133: 3317.

Lee T.I., Rinaldi N.J., Robert F., Odom D.T., Bar-Joseph Z., Gerber G.K., Hannett N.M., Harbison C.T., Thompson C.M., Simon I., et al. 2002. Transcriptional regulatory networks in Saccharomyces cerevisiae. Science 298: 799.

Milo R., Shen-Orr S., Itzkovitz S., Kashtan N., Chklovskii D., and Alon U. 2002. Network motifs: Simple building blocks of complex networks. Science 298: 824.

Muhr J., Andersson E., Persson M., Jessell T.M., and Ericson J. 2001. Groucho-mediated transcriptional repression establishes progenitor cell pattern and neuronal fate in the ventral neural tube. Cell 104: 861

Nüsslein-Volhard C. and Wieschaus E. 1980. Mutations affecting segment number and polarity in Drosophila. Nature 287: 795 .

Ortiz C.O., Etchberger J.F., Posy S.L., Frøkjær-Jensen C., Lockery S., Honig B., and Hobert O. 2006. Searching for neuronal left/right asymmetry: Genome wide analysis of nematode receptor-type guanylyl cyclases. Genetics 173: 131.

Palmer R.E., Inoue T., Sherwood D.R., Jiang L.I., and Sternberg P.W. 2002. Caenorhabditis elegans cog-1 locus encodes GTX/Nkx6.1 homeodomain proteins and regulates multiple aspects of reproductive system development. Dev. Biol. 252: 202.

Pierce-Shimomura J.T., Faumont S., Gaston M.R., Pearson B.J., and Lockery S.R. 2001. The homeobox gene lim-6 is required for distinct chemosensory representations in C. elegans. Nature 410: 694

Poole R. and Hobert O. 2006. Early embryonic programming of neuronal left/right asymmetry in C. elegans. Curr. Biol. (in press).

Ptashne M. 1992. A genetic switch: Phage $\lambda$ and higher organisms. Blackwell Scientific and Cell Press, Cambridge, Massachusetts.

Shen-Orr S.S., Milo R., Mangan S., and Alon U. 2002. Network motifs in the transcriptional regulation network of Escherichia coli. Nat. Genet. 31: 64 .

Stark A., Brennecke J., Bushati N., Russell R.B., and Cohen S.M. 2005. Animal microRNAs confer robustness to gene expression and have a significant impact on $3^{\prime} U T R$ evolution. Cell 123: 1133.

Tsalik E.L. and Hobert O. 2003. Functional mapping of neurons that control locomotory behavior in Caenorhabditis elegans. J. Neurobiol. 56: 178.

Uchida O., Nakano H., Koga M., and Ohshima Y. 2003. The C. elegans che-1 gene encodes a zinc finger transcription factor required for specification of the ASE chemosensory neurons. Development 130: 1215.

White J.G., Southgate E., Thomson J.N., and Brenner S. 1986. The structure of the nervous system of the nematode Caenorhabditis elegans. Philos. Trans. R. Soc. Lond. B Biol. Sci. 314: 1.

Yu S., Avery L., Baude E., and Garbers D.L. 1997. Guanylyl cyclase expression in specific sensory neurons: A new family of chemosensory receptors. Proc. Natl. Acad. Sci. 94: 3384 . 


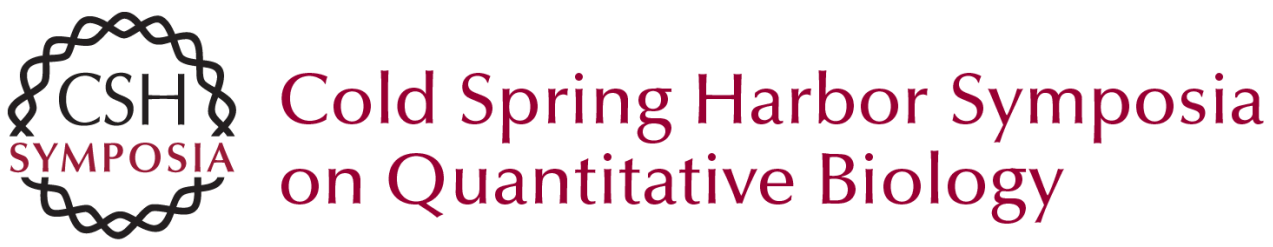

\section{Architecture of a MicroRNA-controlled Gene Regulatory Network That Diversifies Neuronal Cell Fates}

O. HOBERT

Cold Spring Harb Symp Quant Biol 2006 71: 181-188

Access the most recent version at doi:10.1101/sqb.2006.71.006

References This article cites 31 articles, 12 of which can be accessed free at: http://symposium.cshlp.org/content/71/181.full.html\#ref-list-1

License

Email Alerting Receive free email alerts when new articles cite this article - sign up in Service the box at the top right corner of the article or click here. 